\title{
Preserved musical abilities following right temporal lobectomy
}

\author{
Atsushi Koike, M.A., Hiroyuki Shimizu, M.D., Ichiro Suzuki, M.D., Buichi Ishijima, M.D., and \\ Morihiro Sugishita, Dr. H.S., Dr. M.S.
}

Department of Psychology, Sophia University, Tokyo, Japan; Department of Neurosurgery, Tokyo Metropolitan Neurological Hospital, Tokyo, Japan; and Tokyo Metropolitan Fuchu Medical Center for the Severely Handicapped, Tokyo, Japan; Department of Neurosurgery and Department of Cognitive Neuroscience, Research Institute of Logopedics and Phoniatrics, Faculty of Medicine, University of Tokyo, Tokyo, Japan

It has been widely accepted that the right temporal lobe plays a major role in the processing of music. One of the main lines of evidence was derived from Milner's study, published in 1962, which reported that right temporal lobectomy led to a decline in patient scores on four of the six subtests (Tonal Memory, Timbre, Loudness, and Time subtests) of the Seashore Measures of Musical Talents. That finding had led some surgeons and patients to hesitate in choosing right temporal lobectomy as a treatment for intractable epilepsy. The authors examined performance on the Seashore Measures before and after operations in 20 patients with right temporal lobectomy and nine patients with left temporal lobectomy. No disturbances in the Seashore Measures were detected after temporal lobectomy on either side. The extent of these temporal lobectomies was smaller than that of the temporal lobectomies in Milner's study, as measured along the sylvian fissure $(1.5-4 \mathrm{~cm}$; mean $2.7 \mathrm{~cm}$, standard deviation (SD) $0.92 \mathrm{~cm}$ ) and the base of the temporal lobe $(3.5-5.5 \mathrm{~cm}$; mean $4.7 \mathrm{~cm}$, SD $0.63 \mathrm{~cm})$. These findings indicate that the region resected on right temporal lobectomy in the present study is not essential for basic musical processing.

Key Words * temporal lobectomy * Seashore Measures test * music* neuropsychological effect * right temporal lobe * brain

The right temporal lobe is believed to play a major role in the processing of music. Some standard textbooks[3,4,9] state that one of the main lines of evidence was derived from Milner's study,[7] which reported that right temporal lobectomy led to a decline in scores on four of the six subtests (Tonal Memory, Timbre, Loudness, and Time subtests) of the Seashore Measures of Musical Talents.[12] This evidence has discouraged acceptance of right temporal lobectomy as a treatment for intractable epilepsy. In recent surgery, the extent of removal of the temporal lobe has been smaller than that in previous studies, sparing the posterior temporal lobe.[14] We think that smaller resections in right temporal lobectomy may not cause impairment of musical ability. The purpose of this study was to clarify whether scores were impaired on the Seashore Measures of Musical Talents in patients who underwent right or left temporal lobectomy when a smaller resection was made. 


\section{CLINICAL MATERIAL AND METHODS}

\section{Patient Population}

The individuals studied consisted of 29 patients with medically resistant complex partial seizures of medial temporal lobe origin. All patients were right handed with left hemisphere dominance for speech confirmed via the Amytal test. The postoperative Full Scale intelligence quotients (FIQs) of all 29 patients were higher than 85. All the patients had pure tone air-conduction thresholds of less than $20 \mathrm{~dB}$ between 500 and $2000 \mathrm{~Hz}$, and the interaural pure tone average difference was less than $5 \mathrm{~dB}$.[1]

The extent of lateral cortical resection was tailored according to the distribution of the epileptic area. The first type of right temporal lobectomy was performed in 10 of the 29 patients. Preoperative magnetic resonance (MR) imaging was performed using a 0.5-tesla imaging system to detect hippocampal abnormality. The assessment of hippocampal atrophy was based on a visual estimation of the size of the medial temporal lobe and the temporal horn of the lateral ventricle. Preoperative MR imaging showed abnormal findings in all 10 patients: four patients exhibited high intensity in the right hippocampus on T2-weighted MR images (one of the four had early-onset seizures (at $3 / 45$ years of age)); three patients showed atrophy of the hippocampus (one of the three had early-onset seizures); two patients showed high intensity on T2-weighted MR images and atrophy of the hippocampus; and the remaining patient displayed high intensity in the right parahippocampal gyrus on T2-weighted images. The extent of resection was 1.5 to $4 \mathrm{~cm}$ (mean $2.7 \pm 0.92 \mathrm{~cm}$ ( \pm standard deviation)) along the right sylvian fissure and 3.5 to $5.5 \mathrm{~cm}$ (mean $4.7 \pm 0.63 \mathrm{~cm}$ ) along the base of the right temporal lobe (Fig. 1A). The surgeon removed the anterior parts of the superior, middle, and inferior temporal gyri as well as the anterior parts of the fusiform gyrus, the parahippocampal gyrus, and the hippocampus. Furthermore, almost all of the amygdaloid nucleus, the uncus, the temporal pole, the anteroinferior part of the temporal stem, and the anterior part of the collateral isthmus were resected. The extent of hippocampal removal was 1.5 to $3 \mathrm{~cm}$ (mean $2.3 \pm 0.49 \mathrm{~cm}$ ). 


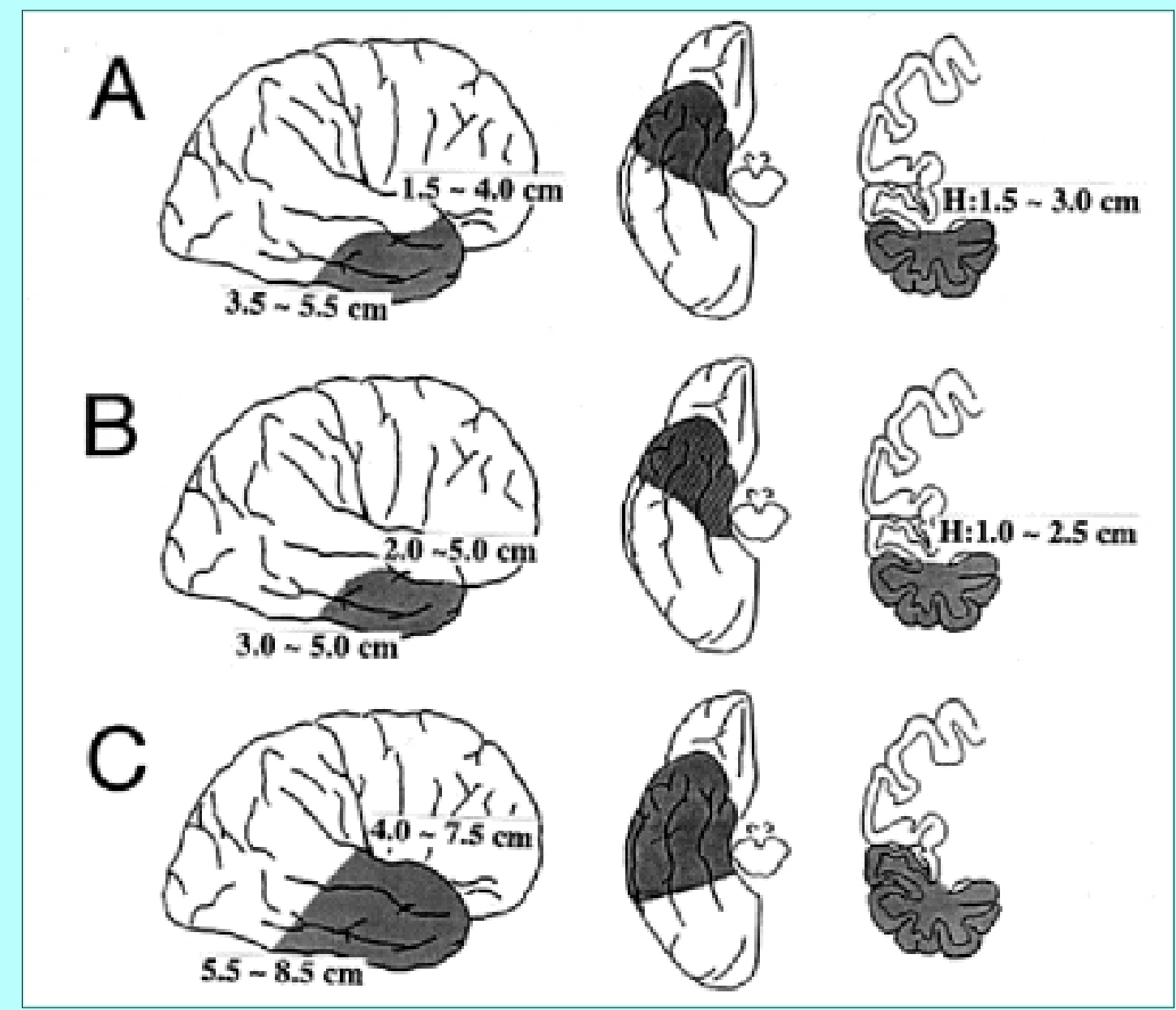

Fig. 1. Drawings showing extent of resection. Shaded areas indicate the extent of the first type of right temporal lobectomy (A) and the second type of right temporal lobectomy (B). The approximate extent of right temporal lobectomy in Milner's study is also shown (C). $\mathrm{H}$ = hippocampus.

The second type of right temporal lobectomy was performed in another 10 of the 29 patients. Preoperative MR imaging revealed abnormal findings in nine of these 10 patients: four of them had atrophy of the right hippocampus; one patient showed high intensity in the right hippocampus on T2-weighted MR images, two exhibited high intensity on T2-weighted MR images and atrophy of the right hippocampus, and two patients had tumors, one of which was an astrocytoma in the right fusiform gyrus, and the other a gangliocytoma in the right uncus in a patient who had early-onset seizures. The extent of resection was 2 to $5 \mathrm{~cm}$ (mean $3.6 \pm 0.83 \mathrm{~cm}$ ) from the tip of the right temporal lobe along the superior margin of the right middle temporal gyrus, and 3 to $5 \mathrm{~cm}$ (mean $4.2 \pm 0.67 \mathrm{~cm}$ ) along the base of the right temporal lobe. The operation spared the right superior temporal gyrus, in contrast with the first type of right temporal lobectomy (Fig. 1B). The extent of hippocampal removal was 1 to $2.5 \mathrm{~cm}$ (mean 2 $\pm 0.47 \mathrm{~cm})$.

Left temporal lobectomy was performed in the remaining nine patients. The first type of left temporal lobectomy, which spared the left superior temporal gyrus, was performed in seven of the nine patients. Preoperative MR imaging showed abnormal findings in four of these seven patients: two had atrophy of the left temporal lobe, one displayed high intensity and atrophy of the left hippocampus on T2-weighted MR images, and one had an astrocytoma in the left middle temporal gyrus. The extent of resection was 2 to $5 \mathrm{~cm}$ (mean $3.5 \pm 0.96 \mathrm{~cm}$ ) from the tip of the left temporal lobe along the superior margin of the left middle temporal gyrus, and 3.5 to $5 \mathrm{~cm}$ (mean $4.2 \pm 0.64 \mathrm{~cm}$ ) along the base of the left temporal lobe. 
The operation included removal of the following anatomical structures of the left hemisphere: the anterior parts of the middle and inferior temporal gyri, the anterior part of the fusiform gyrus, the anterior part of the parahippocampal gyrus, almost all of the amygdaloid nucleus, the uncus, the temporal pole, the anteroinferior part of the temporal stem, and the anterior part of the collateral isthmus. The left hippocampus was resected in six of the seven patients. The extent of hippocampal removal was 1.5 to 2.5 $\mathrm{cm}$ (mean $2.2 \pm 0.41 \mathrm{~cm}$ ).

The second type of left temporal lobectomy, which spared the left superior and middle temporal gyri, was performed in the remaining two patients. Preoperative MR imaging showed no abnormal findings in these two patients. The extent of resection was 3.5 to $4 \mathrm{~cm}$ (mean $3.75 \pm 0.35 \mathrm{~cm}$ ) from the tip of the left temporal lobe along the superior margin of the left inferior temporal gyrus, and 3.5 to $4 \mathrm{~cm}$ (mean $3.75 \pm$ $0.35 \mathrm{~cm}$ ) along the base of the left temporal lobe. The left hippocampus was resected in these two patients. The extent of hippocampal removal was 1.5 or $2 \mathrm{~cm}$ (mean $1.75 \mathrm{~cm}$ ).

In addition to the surgically treated patients, a group of 20 right-handed healthy volunteers was tested for comparison.

\section{Tests and Procedures}

To assess musical ability, various batteries of tests have been constructed. One of the most popular is the Seashore Measures of Musical Talents.[12] This battery contains six subtests as follows:

1) Pitch subtest. Fifty pairs of tones are presented; in each pair the participant determines whether the second tone is higher or lower in pitch than the first.

2) Loudness subtest. Fifty pairs of tones are presented. The participant indicates for each pair whether the second tone is stronger or weaker than the first.

3) Rhythm subtest. Thirty pairs of rhythmic patterns comprise the rhythm test. The participant indicates whether the two patterns in each pair are the same or different.

4) Time subtest. The test of the sense of time consists of 50 pairs of tones of different durations. The individual determines whether the second tone is longer or shorter than the first.

5) Timbre subtest. This test consists of 50 pairs of tones. In each pair the participant judges whether the tones are the same or different in timbre or tone quality.

6) Tonal Memory subtest. This test has 30 pairs of tonal sequences consisting of 10 items, each of three-, four-, and five-tone spans. In each pair, one note is different in the two sequences, and the individual identifies which note it is by number.

The Seashore Measures of Musical Talents was administered to each participant in a soundproof room. The tape was played using a digital audio tape recorder connected to a two-channel audiometer (RION AA-63BN). A stereo headphone (RION AD-02) set at approximately $70 \mathrm{~dB}$ A (dB weighted by A scale) per channel was used to transmit stimulus sounds to the participant. Each individual was instructed to record responses on the recording paper. All patients were tested before and 2 to 5 weeks after surgery (mean $3.3 \pm 1.01$ weeks). 


\section{TABLE 1}

DEMOGRAPHIC CHARACTERISTICS OF 29 PARTICIPANTS IN A STUDV OF MUSICAL ABILTV AFTER RIGHT TEMPORAL LOBECTOMN ${ }^{\star}$

\begin{tabular}{|c|c|c|c|c|c|c|c|c|}
\hline $\begin{array}{l}\text { Group \& } \\
\text { Type of } \\
\text { Resection }\end{array}$ & $\begin{array}{l}\text { No. of } \\
\text { Parbici- } \\
\text { pants }\end{array}$ & $\begin{array}{l}-S^{-x} \\
\text { (Mif) }\end{array}$ & Age (yrs] & $\begin{array}{l}\text { Education } \\
\text { (yrs) }\end{array}$ & $\begin{array}{c}\text { Age at } \\
\text { Seizure } \\
\text { Orset (yrs) }\end{array}$ & SPI (days) & ITI (days] & Postop $\mathrm{FIQ}$ \\
\hline RTL group & 20 & $10: 10$ & $28.0 \pm 6.96$ & $13.6 \pm 2.35$ & $10.3 \pm 5.39$ & $23.1 \pm 6.56$ & $34.4 \pm 5.43$ & $100.3 \pm 10.64]$ \\
\hline first type & 10 & 6.4 & $28.3 \pm 7.35$ & $13.4 \pm 2.32$ & $10.6 \pm 6.23$ & $20.1 \pm 6.54$ & $34.0 \pm 4.76$ & $96.9 \pm 9.47]$ \\
\hline second type & 10 & $4: 6$ & $27.6 \pm 6.93$ & $13.7 \pm 2.50$ & $10.0 \pm 4.74$ & $26.0 \pm 5.35$ & $34.8 \pm 6.27$ & $103.7 \pm 11.13 \mathrm{j}$ \\
\hline LTL group & 9 & $7: 2$ & $35.7 \pm 10.22$ & $12.8 \pm 2.22$ & $14.9 \pm 6.35$ & $23.4 \pm 8.50$ & $38.6 \pm 9.06$ & $93.3 \pm 7.78$ \\
\hline first type & 7 & 5.2 & $6 \pm 11.60$ & $13.0 \pm 2.52$ & $14.1 \pm 7.08$ & $25.0 \pm 8.98$ & $40.3 \pm 9.32$ & $90.9 \pm 3.89$ \\
\hline secondtype & 2 & $2: 0$ & \pm 2.12 & $12.0 \pm 0.00$ & $17.5 \pm 2.12$ & $18.0 \pm 4.24$ & $32.5 \pm 6.36$ & $102.0 \pm 14.14]$ \\
\hline control group & 20 & $12: 8$ & & $15.0 \pm 3.48$ & NA & NA & $32.4 \pm 6.87$ & NA \\
\hline
\end{tabular}

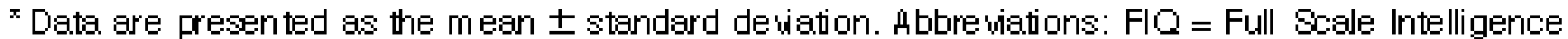
Quotient; $I T I=$ intertest interval; $L T L=$ left tem poral lobectom $y$; $N A=$ not applicable; $R T L=$ right temporal lobectom y; SRI = surgeryto-re test inter val.

Demographic characteristics of the two patient groups and the normal control group are presented in Table 1. There were no significant differences between the three groups in education and intertest interval. No significant differences were noted between the two patient groups in the age at seizure onset, surgery-to-retest interval and FIQ. There was no difference in age between the patients who underwent right temporal lobectomy and the normal control group, whereas the mean age for the patients undergoing left temporal lobectomy was older than that of the patients who underwent right temporal lobectomy $(\mathrm{t}(27)=2.383, \mathrm{p}<0.05)$ and the normal group $(\mathrm{t}(27)=3.995, \mathrm{p}<0.001)$.

\section{Statistical Analysis}

Two different statistical approaches, Student's paired t-test and one-way analysis of variance (ANOVA), were used to analyze the results.

\section{RESULTS}

Because there were no significant differences between the scores seen in the patients undergoing the first type and those undergoing the second type of right temporal lobectomy, the results of the patients who underwent the first and second type were combined. The results of the patients undergoing the first and second type of left temporal lobectomy were also combined for the same reason. The means and standard deviations for each subtest of the Seashore Measures before and after surgery for the two patient groups (right temporal lobectomy group and left temporal lobectomy group) are presented in Table 2 . The results of the first and second testings for the normal control group are also presented.

The paired t-test was used to identify the difference between the preoperative and postoperative scores of each of the two patient groups (right and left temporal lobectomy group). The paired t-test was also used to identify the difference between the first and second testing scores of the normal control group. Statistically significant results were obtained only in the Pitch subtest (Table 2). The results of paired $\mathrm{t}$-test analysis demonstrated that the postoperative scores of the patients with right temporal lobectomy significantly increased over the preoperative scores $(\mathrm{t}(19)=3.612, \mathrm{p}<0.01)$. The same result was obtained in the patients with left temporal lobectomy $(\mathrm{t}(8)=2.991, \mathrm{p}<0.05)$. 
TABLE 2

MEAN SCORES AND STANDARD DEVMTIONS FOR THE SEASHORE MEASURES STRAT IF IEd BV GROU *

\begin{tabular}{|c|c|c|c|c|c|c|}
\hline \multirow[b]{2}{*}{$\begin{array}{l}\text { Group \& Time } \\
\text { of Testing }\end{array}$} & \multicolumn{6}{|c|}{ Subtest } \\
\hline & Pitch & Loudness & Rhythm & Time & Timbre & $\begin{array}{l}\text { Tonal } \\
\text { Memary }\end{array}$ \\
\hline \multicolumn{7}{|l|}{$\begin{array}{l}\text { RTL group } \\
\text { (20 patients) }\end{array}$} \\
\hline $\begin{array}{l}\text { preop } \\
\text { postop }\end{array}$ & $\begin{array}{r}36.4 \pm 6.87 \\
39.2 \dagger \pm 6.06\end{array}$ & $\begin{array}{l}43.7 \pm 6.07 \\
46.0 \pm 3.03\end{array}$ & $\begin{array}{l}23.2 \pm 3.58 \\
23.3 \pm 3.47\end{array}$ & $\begin{array}{l}39.4 \pm 4.18 \\
41.4 \pm 3.60\end{array}$ & $\begin{array}{l}40.5 \pm 4.65 \\
41.8 \pm 4.16\end{array}$ & $\begin{array}{l}23.7 \pm 4.22 \\
23.6 \pm 3.61\end{array}$ \\
\hline $\begin{array}{l}\text { LTL group } \\
\text { (9 patients) }\end{array}$ & & & & & & \\
\hline preop & $32.3 \pm 6.80$ & $40.6 \pm 10.40$ & $21.9 \pm 2.76$ & $38.8 \pm 5.85$ & $40.3 \pm 5.17$ & $19.7 \pm 4.69$ \\
\hline $\begin{array}{c}\text { postop } \\
\text { control group } \\
\text { (20 iolunteers) }\end{array}$ & $35.6 \ddagger \pm 5.40$ & $41.0 \pm 8.79$ & $22.4 \pm 1.94$ & $40.0 \pm 5.05$ & $40.3 \pm 4.18$ & $18.3 \pm 6.02$ \\
\hline 1st testing & $41.7 \pm 6.82$ & $45.3 \pm 3.56$ & $25.8 \pm 2.05$ & $44.3 \pm 3.96$ & $43.4 \pm 5.68$ & $27.0 \pm 2.51$ \\
\hline 2nd testing & $43.5 \pm 5.22$ & $46.3 \pm 2.60$ & $26.2 \pm 1.99$ & $42.9 \pm 5.77$ & $44.1 \pm 4.96$ & $26.9 \pm 2.50$ \\
\hline
\end{tabular}

One-way ANOVAs were used to compare the three groups (right temporal lobectomy, left temporal lobectomy, and normal control groups) in terms of the difference scores in the six subtests. The difference score consisted of the postoperative minus preoperative score in the two groups of patients. In the normal control group the difference score was the second minus the first testing score. There were no significant differences between the difference scores of the three groups in any of the six subtests.

In summary, two analyses revealed that performance on any of the six subtests of the Seashore Measures was not impaired on retesting in any group. No statistically significant differences were noted between the three groups in the subtests.

The right temporal lobectomy group included three patients with early-onset seizures (age $3 / 45$ years), and the left temporal lobectomy group included no such patients. An analysis excluding these three patients was performed to clarify whether the right temporal lobectomy caused impairment of musical abilities in the patients with late onset seizure.

The results of paired t-test analysis revealed that the postoperative scores of the patients with right temporal lobectomy significantly increased over the preoperative scores in the Pitch $(\mathrm{t}(16)=3.414, \mathrm{p}<$ $0.01)$ and the Loudness $(t(16)=2.765, \mathrm{p}<0.05)$ subtests. Statistically significant results were not obtained in the other four subtests. One-way ANOVAs demonstrated that there were no significant differences between the difference scores of the three groups in any of the six subtests. In summary, two analyses showed that performance on any of the six subtests was not impaired on retesting in the right temporal lobectomy group with late-onset seizures. There were no significant differences between the three groups in the subtest scores.

We compared the scores of patients with hippocampal abnormality on preoperative MR imaging to those of patients with no hippocampal abnormality for each subtest. In the right temporal lobectomy group, 19 of the 20 patients exhibited hippocampal abnormality on preoperative MR imaging and the remaining patient did not. The score of the patient with no hippocampal abnormality was within the range of the mean score plus or minus two standard deviations of the patients with hippocampal abnormality in any of the six subtests. In the left temporal lobectomy group, five of the nine patients revealed no hippocampal 
abnormality on preoperative MR imaging and the remaining four displayed hippocampal abnormality. The mean score of the patients with hippocampal abnormality was within the range of the mean score plus or minus two standard deviations in any of the six subtests of the patients without hippocampal abnormality.

\section{DISCUSSION}

Milner[7] reported that right temporal lobectomy impaired performance on four subtests (Loudness, Time, Timbre, and Tonal Memory subtests) of the Seashore Measures of Musical Talents. In contrast, our study revealed that right and left temporal lobectomy did not cause impairment in any of the six subtests. The inconsistency between our results and those of Milner might be attributable to the fact that the right temporal lobectomies in our patients were less extensive than those of Milner's patients. The extent of the resection by right temporal lobectomy in Milner's study was 4 to $7.5 \mathrm{~cm}$ along the sylvian fissure and 5.5 to $8.5 \mathrm{~cm}$ along the base of the temporal lobe (Fig.1C). In contrast, the extent of the resection in our temporal lobectomy was 1.5 to $4 \mathrm{~cm}$ (mean $2.7 \mathrm{~cm}$ ) along the sylvian fissure and 3.5 to $5.5 \mathrm{~cm}$ (mean $4.7 \mathrm{~cm}$ ) along the base of the temporal lobe (Fig.1A and B). Our findings indicate that the region resected by our right temporal lobectomy did not play an important role in the processing of music. This suggestion is supported by a recent positron emission tomography study using Seashore's Tonal Memory and Timbre subtests. Mazziotta, et al.,[6] reported that the most activated region was the right temporoparietal junction and that the bilateral anterior temporal lobes were not activated.

Saykin, et al.,[11] reported that left temporal lobectomy caused verbal memory disturbance in patients with late-onset seizures but not in patients with early-onset seizures. Based on this observation, our inability to detect disturbance in musical skills would not be surprising. If all of our subjects had been patients with early-onset seizures, they would not have shown the disturbance. However, only three patients in our study were early-onset patients. The analysis excluding these three patients still showed no impairment in musical abilities.

Kester, et al.,[5] investigated whether patients who underwent right temporal lobectomy showed impairment in the short version of one subtest (Tonal Memory) of the Seashore Measures. Although the extent of resection in their patients was almost the same as that in Milner's patients, they found that right temporal lobectomy did not cause impairment in the Tonal Memory subtest, which is inconsistent with the findings of Milner's study. The inconsistency may have been caused by the use of the short version of the subtest. Further studies are needed to define to what extent the length of resection in right temporal lobectomy causes impairment in the Seashore Measures.

The tasks of musical ability, which are similar to the Seashore Measures, were administered to patients with right temporal lobectomy by Zatorre[16] and by Samson and Zatorre.[10] Zatorre[16] reported that the patients studied had impairment in pitch perception. Samson and Zatorre[10] also demonstrated that their patients were impaired in melodic (Tonal Memory) and chord discrimination (Timbre). Because neither of the studies examined preoperative performance of the patients, it is not clear that their right temporal lobectomy caused the impairment.

Milner[7] reported that the Rhythm subtest of the Seashore Measures did not discriminate between patients with right and left temporal lobectomies. The same result was obtained in the studies of Boone and Rausch[2] and in the present study. Boone and Rausch also showed that neither right nor left temporal lobectomy caused impairment in the Rhythm subtest. However, they compared the preoperative score of the test with the score obtained 1 year after the operation. Interpretation of these results is 
complicated by the possibility of recovery during a year. The present study provided stronger evidence for the absence of a deficit, because our patients were tested 2 to 5 weeks postoperatively. Comparison of these test scores with preoperative test scores indicated no disturbance in the Rhythm subtest following right or left temporal lobectomy.

In addition to the disturbance of musical abilities revealed by Milner's study,[7] many neuropsychological side effects have been reported to occur after right temporal lobectomy, such as impairment in the delayed recognition of familiar faces,[8] in recall of the Rey-Osterrieth Complex Figure,[15] and in recall of spatial location.[13] However, interpretation of the results of these studies is difficult, because the extent of removal of the right temporal lobe in these studies was as large as that in Milner's study. Our inability to detect deficits in musical skill in patients with late-onset seizure suggests that other previously described side effects may also not be observed when the extent of resection of the right temporal lobe is small.

\section{References}

1. American National Standards Institute: Specifications for Audiometers (ANSI S3.6-1967). New York: ANSI, 1969

2. Boone KB, Rausch R: Seashore Rhythm Test performance in patients with unilateral temporal lobe damage. J Clin Psychol 45:614-618, 1989

3. Goodglass H, Butter N: Psychobiology of cognitive process, in Atkinson RC, Herrnstein RJ, Lindzey G, et al (eds): Stevens' Handbook of Experimental Psychology. Vol 2: Learning and Cognition, ed 2. New York: John Wiley \& Sons, 1988, pp 863-952

4. Henson RA: Amusia, in Frederiks JAM (ed): Handbook of Clinical Neurology. Vol 1: Clinical Neuropsychology. New York: Elsevier, 1985, pp 483-490

5. Kester DB, Saykin AJ, Sperling MR, et al: Acute effect of anterior temporal lobectomy on musical processing. Neuropsychologia 29:703-708, 1991

6. Mazziotta JC, Phelps ME, Carson RE, et al: Tomographic mapping of human cerebral metabolism: auditory stimulation. Neurology 32: 921-937, 1982

7. Milner B: Laterality effects in audition, in Mountcastle VB (ed): Interhemispheric Relations and Cerebral Dominance. Baltimore: The John Hopkins Press, 1962, pp 177-195

8. Milner B: Visual recognition and recall after right temporal-lobe excision in man. Neuropsychologia 6:191-209, 1968

9. Poeck K: Temporal lobe syndromes, in Frederiks JAM (ed): Handbook of Clinical Neurology. Vol 1: Clinical Neuropsychology. New York: Elsevier, 1985, pp 43-48

10. Samson S, Zatorre RJ: Melodic and harmonic discrimination following unilateral cerebral excision. Brain Cogn 7:348-360, 1988

11. Saykin AJ, Gur RC, Sussman NM, et al: Memory deficits before and after temporal lobectomy: effect of laterality and age of onset. Brain Cogn 9:191-200, 1989 
12. Seashore CE, Lewis D, Saetveit JG: Seashore Measures of Musical Talents. Manual (Revised 1960). New York: The Psychological Corp, 1960

13. Smith ML, Milner B: The role of the right hippocampus in the recall of spatial location.

Neuropsychologia 19:781-793, 1981

14. Spencer DD, Ojemann GA: Overview of therapeutic procedures, in Engel J Jr (ed): Surgical Treatment of the Epilepsies, ed 2. New York: Raven Press, 1993, pp 455-471

15. Taylor LB: Localization of cerebral lesions by psychological testing. Clin Neurosurg 16:269-287, 1969

16. Zattore RJ: Pitch perception of complex tones and human temporal-lobe function. J Acoust Soc Am 84:566-572, 1988

Manuscript received February 13, 1996.

Accepted in final form July 5, 1996.

Address reprint requests to: M. Sugishita, Dr. H.S., Dr. M.S., Department of Cognitive Neuroscience, Research Institute of Logopedics and Phoniatrics, Faculty of Medicine, University of Tokyo, 7-3-1 Hongo, Bunkyo-ku, Tokyo 113, Japan. 